Dicle University Journal of Engineering (DUJE)

web: http://dergipark.gov.tr/dumf

Araştırma Makalesi / Research Article

\title{
Alüminyum Alaşımlı Otomobil Jantlarında Deneysel Darbe Testlerinin Sonlu Elemanlar Yöntemiyle Doğrulanması
}

\author{
Validation of Experimental Impact Tests on Aluminum Alloy Car Wheels using the \\ Finite Element Method \\ Emrah AYRAN ${ }^{1,2}$, Mahmut PEKEDís ${ }^{1 *}$ \\ ${ }^{1}$ Ege Üniversitesi, Makina Mühendisliği Bölümü, İzmir, emrah.ayran@maxionwheels.com, mahmut.pekedis@ege.edu.tr \\ ${ }^{2}$ Maxion İnci Jant Sanayi A. Ş, Manisa, emrah.ayran@maxionwheels.com
}

\begin{tabular}{|c|c|}
\hline MAKALE BİLGİLERİ & ÖZET \\
\hline Makale geçmişi: & $\begin{array}{l}\text { Jantlar için gerçekleştirilen sanal gerçekçi simülasyonların hassasiyeti, ağırlıklı olarak üretim sürecinde } \\
\text { karşılaşılan değişken faktörlerin analizlere dahil edilmesine bağlıdır. Buna ek olarak, şekil değiştirme hız etkisi }\end{array}$ \\
\hline Geliş: 26 Kasım 2019 & de simülasyon gerçekliğini etkileyen bir diğer faktördür. Burada, bu etkiyi malzeme modellerine dâhil edip daha \\
\hline Düzeltme: 11 Mart 2020 & doğru analizlerin gerçekleştirilmesini hedefliyoruz. Başlangıçta jantlardan çıkartılan çekme testi numuneleri 0.1, \\
\hline Kabul: 23 Mayıs 2020 & $1,10,100$ ve $600 \mathrm{~mm} / \mathrm{dk}^{\prime} l ı k$ şekil değişim hızlarında test edilip elde edilen ölçümler, Johnson-Cook malzeme \\
\hline Anahtar kelimeler: & $\begin{array}{l}\text { modelinde işlenerek malzeme katsayıları bulunmuştur. Sonra, standart olarak kullanılan malzeme katsayılar ile } \\
\text { şekil değişim hız etkisini içeren bu katsayılar jant darbe analizlerine dâhil edip simülasyonlar gerçekleştirilmiş }\end{array}$ \\
\hline $\begin{array}{l}\text { Alüminyum alaşımlı jant, sonlu } \\
\text { elemanlar yöntemi, şekil değişim } \\
\text { hızı, Johnson-Cook malzeme } \\
\text { modeli, darbe testi. }\end{array}$ & $\begin{array}{l}\text { ve her ikisinin sonucu deneysel verilerle karşılaştırılmıştır. Farklı şekil değiştirme hızında test edilen } \\
\text { numunelerdeki akma ve kopma gerilmelerinin } 10 \mathrm{~mm} / \mathrm{dk}^{\prime} \text { daki hızla maksimum değerlere ulaştı̆̆ gözlenmiştir. } \\
\text { Elden edilen sonuçlardan, şekil değişim hızı etkisinin tanımlandığı simülasyonların deneysel darbe verileriyle } \\
\text { daha uyumlu olduğu gözlenmiştir. Sonuç olarak, şekil değişim hızının nümerik sonuçlar üzerinde etkili olduğu } \\
\text { ve daha gerçekçi simülasyonlar elde edilmesi için bunların bünyesel malzeme modeline katılması gerektiği } \\
\text { çıkarımı yapılmıştır. }\end{array}$ \\
\hline
\end{tabular}

Doi: 10.24012/dumf.651318

\begin{tabular}{|c|c|}
\hline ARTICLE INFO & ABSTRACT \\
\hline $\begin{array}{l}\text { Article history: } \\
\text { Received: } 26 \text { December } 2019 \\
\text { Revised: } 11 \text { March } 2020 \\
\text { Accepted: } 23 \text { May } 2020\end{array}$ & $\begin{array}{l}\text { The sensitivity of realistic simulations carried out for car wheels are heavily dependent on whether the variable } \\
\text { factors encountered during manufacturing are included into the analysis. Additionally, the strain rate is also one } \\
\text { another factor that affects the reality of the simulation. Here, we aim to perform more accurate analysis by } \\
\text { incorporating the strain rate effect into the material model. Initially, tensile test specimens that extracted from the } \\
\text { wheels are tested at various strain rates such as } 0.1,1,10,100 \text { and } 600 \mathrm{~mm} / \mathrm{min} \text { to determine material parameters }\end{array}$ \\
\hline $\begin{array}{l}\text { Aluminum alloy wheels, finite } \\
\text { element method, strain rate, } \\
\text { Johnson-Cook material model, } \\
\text { impact test }\end{array}$ & $\begin{array}{l}\text { by processing the measurements in Johnson Cook material model. Then, numerical analyses are carried out for } \\
\text { the wheels to simulate the impact test for two material models which the } 1 \text { st includes the strain rate effect, while } \\
\text { the } 2 \text { nd does not. It is observed that the tensile and failure stresses have reached the maximum values for the } \\
\text { tensile specimens tested at various strain rates. The results have shown the simulations that performed with strain } \\
\text { rate effects are in more agreement with experimental impact data. As a result, it is concluded that the strain rate } \\
\text { affects the numerical data which shows that it should be included in constitutive material model to obtain more } \\
\text { realistic simulations. }\end{array}$ \\
\hline
\end{tabular}

* Sorumlu yazar / Correspondence

Mahmut PEKEDIS

$\bowtie$ mahmut.pekedis@ege.edu.tr 


\section{Giriş}

Jant, halk arasında her ne kadar görselliğin ön planda tutulduğu bir parça olarak yorumlansa da, aslında bu görselliğinin yanında araçtaki en önemli emniyet parçalarından birisidir. Otomotiv endüstrisindeki en önemli konulardan birisi yakıt tüketimini azaltma çalışmalarıdır. Yakıt tüketimini azaltmak için de araçlarda daha hafif malzemeler kullanılmaya başlanmış ve ağırlı azaltma çalışmaları üzerine yoğunlaşılmıştır. Ağırlığın azaltılmasının yanında güvenlikten de ödün verilmemesi gerektiğinden, otomotiv endüstrisi düşük yoğunluklu ve yüksek mukavemetli malzemelere yönelmiştir. Alüminyum alaşımlarının hafif ve yüksek mukavemetli olmasının yanında farklı özelliklerinin de olması bu alaşımın jant endüstrisinde kullanılması birçok avantaj1 da beraberinde getirmiștir. Yeni bir jant tasarımı yapılırken göz önünde bulundurulması gereken bazı noktalar vardır. Öncelikle jantın, belirlenen araç yükünü karşılayabilecek mukavemete sahip olması gerekmektedir. Dayanıklılığın yanı sıra hafiflik de çok önemli bir koşuldur. Bu nedenle jantın yük taşımayan bölgelerine ağırlığı azaltmak için çeşitli boşaltmalar da tasarlanabilmektedir. Tüm bunların yanında jant, birlikte araca monte edilecek diğer parçalarla (bijon, porya, lastik vb.) da uyumlu olması gerekmektedir. Aynı şekilde jantın çalışma koşullarında da yeterli dayanım koşullarını sağlaması gerekir.

Hâlihazırda, jantlara ilişkin geliştirme sürecinde farklı mekanik performans testleri uygulanmaktadır [1-3]. Jantların, gerçek ortamda maruz kalabilecekleri yanal darbelere karşı dayanımları "13 ${ }^{\circ}$ darbe testi", viraj boyunca üzerlerinde oluşan kuvvetler "köşe yorulma testi" ve dönme aşamasında oluşan kuvvetler "radyal yorulma testi" ile belirlenir [14]. Ancak bu testler çoğu zaman maliyetli ve bazen uzun süre alabilmektedir [5, 6]. Diğer taraftan bilgisayar teknolojisindeki ilerlemeler, daha hızlı ve gerçekçi sayısal simülasyonların gerçekleştirilmesine olanak sağlayıp son zamanlarda jant endüstrisinde de yansımaları olmuştur $[6,8]$. Bu sayısal simülasyonlar da çözücü olarak yaygın olan sonlu elemanlar yöntemi (SEY) kullanılmaktadır. Bu yöntem kullanılarak alüminyum alaşımlı jantlarda uygulanan $13^{\circ}$ lik darbe testinin simülasyonları birkaç çalışmada sunulmuştur [6-8]. Yine bir başka çalışmada, $90^{\circ}$ lik darbe testi SEY ile analiz edilip Von Mises gerilme sonuçları zamana bağlı olarak verilmiştir [5]. Diğer taraftan SEY'den elde edilen simülasyonların hassasiyeti, uygulanan analiz tipi (statik, implicit-explicit dinamik), ağ (quad, hex vb.) malzeme modeli (lineer, lineer olmayan, şekil değișim hızı vb.) ve sınır koşulları gibi birçok parametreye bağlı olarak değişmektedir. Özellikle darbe veya çarpışma testlerinde, şekil değișim hızı etkisinden dolayı malzemenin sergilemiş olduğu mekanik davranış değişmekte ve bunun malzeme modeline dahil edilmesi gerekir [9-11]. Ancak, bu faktörün literatürde sunulan çalışmalarda ihmal edildiği görülmüştür [5-8]. $\mathrm{Bu}$ araştırmada deneysel olarak elde edilen şekil değişim hız parametrelerinin malzeme modeline katarak daha gerçekçi analizlerin gerçekleştirilmesi hedeflenmiştir.

Çalışmanın akışı şu şekildedir. Önce, jantta kullanılan malzemeye ilişkin mekanik karakterizyondan bahsedilir. Sonra, deneysel ölçümlerin Johnson Cook modeli ile işlenmelerine ve malzeme katsayılarının belirlenmesine yönelik teknik açıklanır. En sonunda da simülasyon ve test sonuçları değerlendirilip birbirleriyle karşılaştırılır.

\section{Malzemenin mekanik karakterizasyonu}

Başlangıçta, A356 alaşımlı malzemeden üretilen jantın 5 kritik feder bölgesinden (yaygın olarak hasarın oluştuğu kısımlar) 3'er numune çıkarılıp farklı hızlarda çekme testlerine tabi tutulmuş ve elde edilen sonuçları Tablo 1'de verilmiștir. $\mathrm{Bu}$ numunelerin çap1 $5 \mathrm{~mm}$ ve gauge boyu ise 33 mm'dir. Aynı şartlar altında ve sıralı olarak dökülen bu jantların, aynı çekme hızındaki test sonuçları arasında Şekil 1'de verildiği üzere az da olsa bir değişkenlik gözlenmektedir. 


\begin{tabular}{ccccc}
\multicolumn{6}{c}{ Tablo 1. Çekme testi sonuçlarl } \\
\hline $\begin{array}{c}\text { Çekme } \\
\text { hız1 } \\
(\mathrm{mm} / \mathrm{dk})\end{array}$ & $\begin{array}{c}\text { Numune } \\
\text { no }\end{array}$ & $\begin{array}{c}\text { Akma } \\
\text { gerilmesi } \\
(\mathrm{MPa})\end{array}$ & $\begin{array}{c}\text { Kopma } \\
\text { gerilmesi } \\
(\mathrm{MPa})\end{array}$ & $\begin{array}{c}\text { Birim şekil } \\
\text { değiştirme } \\
(\%)\end{array}$ \\
\hline \multirow{3}{*}{0.1} & 1 & 196.84 & 253.81 & 4.38 \\
& 2 & 202.12 & 243 & 2.27 \\
& 3 & 188.85 & 240.52 & 3.21 \\
\hline \multirow{2}{*}{1} & 1 & 200.06 & 259.48 & 3.96 \\
& 2 & 192.08 & 245.69 & 3.47 \\
& 3 & 200.27 & 259.16 & 4.20 \\
\hline \multirow{3}{*}{10} & 1 & 203.83 & 259.56 & 3.74 \\
& 2 & 210.15 & 261.95 & 2.88 \\
& 3 & 193.87 & 245.63 & 2.47 \\
\hline \multirow{3}{*}{100} & 1 & 192.16 & 254.35 & 3.53 \\
& 2 & 196.39 & 252.77 & 2.77 \\
& 3 & 193.72 & 248.72 & 2.87 \\
\hline \multirow{2}{*}{600} & 1 & 198.41 & 242.48 & 2.76 \\
& 2 & 195.15 & 252.26 & 3.59 \\
& 3 & 201.50 & 244.78 & 2.77 \\
\hline
\end{tabular}

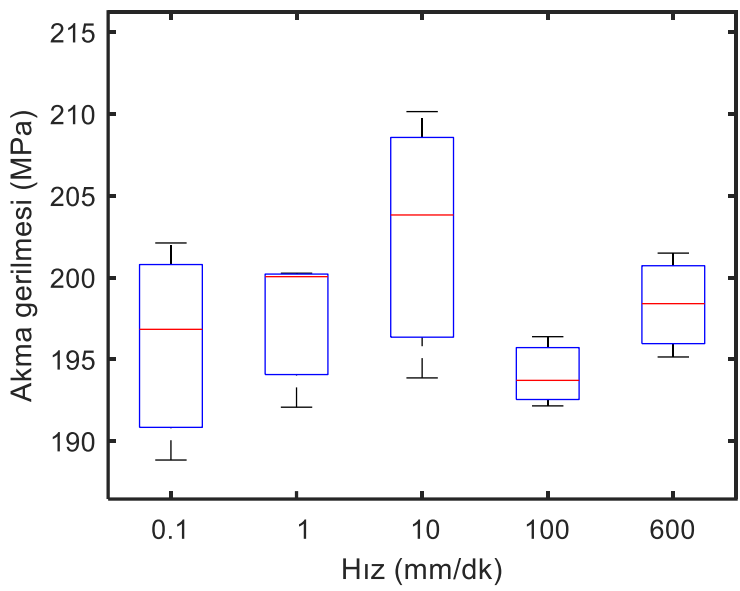

a)

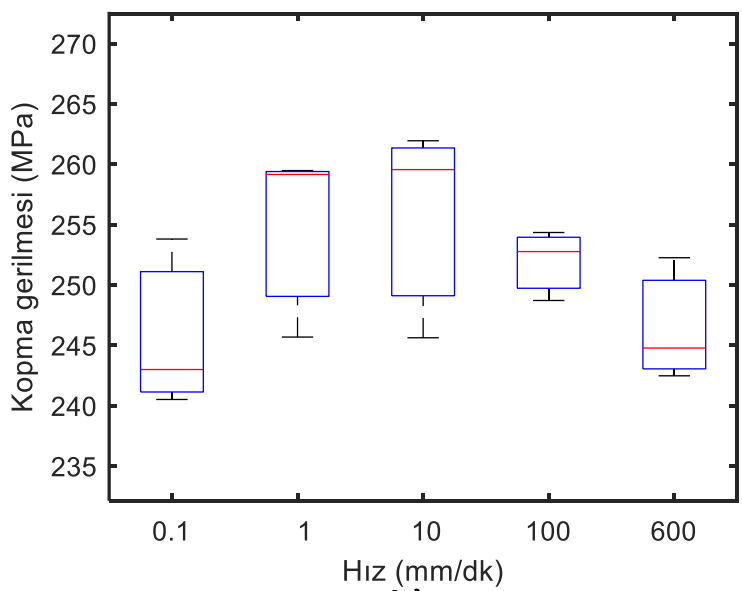

b)

Şekil 1. Çekme hızına bağlı olarak elde edilen malzeme özelliklerinin kutu grafiğindeki dăgllımları, a) Akma gerilmesi, b) Kopma gerilmesi (Kırmızı çizgi medyanı gösterir)
Çok düşük uzama değerleri görülen numuneler incelendiğinde, numune çıkarılan bölgede döküm boşluğu gözlenmiş ve bu kopmayı hızlandırmıştır. $\mathrm{Bu}$ değişkenlik döküm yönteminden ve jant tasarımindan kaynaklanmaktadır. Dökümde; dolumu ve katılaşmayı etkileyen her türlü faktör jantın mekanik özelliklerine etki etmektedir. Bu faktörler de çok fazla olduğu için bu değişkenlik belli oranda görülebilmektedir. Akma ve kopma gerilmesi açısından karşılaştırıldığında, 10 $\mathrm{mm} / \mathrm{dk}$ hıza kadar artış sonrada düşüş gözlenmiştir (Şekil 1). Maksimum birim şekil değişimi ise $1 \mathrm{~mm} / \mathrm{dk}$ hızında gerçekleşmiştir (Şekil 2). Gruplar içerisinde farklilıklar görülmüş ve bu amaçla medyan bölgesinde kalan numuneler seçilip malzeme modellerinde kullanılmıştır.

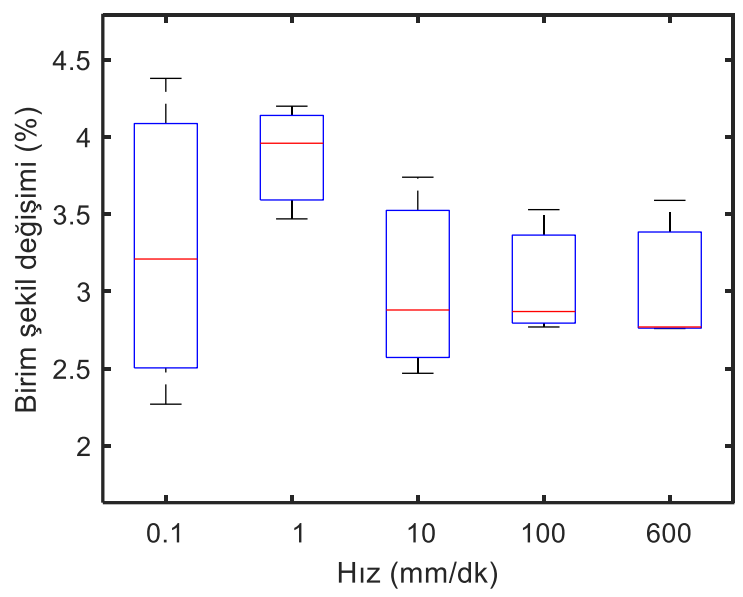

Şekil 2. Çekme hızına bağll olarak elde edilen birim şekil değişim verilerinin kutu grafiğindeki dağılımları, (Kırmızı çizgi medyanı gösterir)

Seçilen numunelere ilişkin gerilme-şekil değişimi grafikleri Şekil 3'te gösterilmiştir. Bu grafikten görüldügü üzere çekme hızı arttıkça akma ve kopma gerilmesi artmaktadir. 


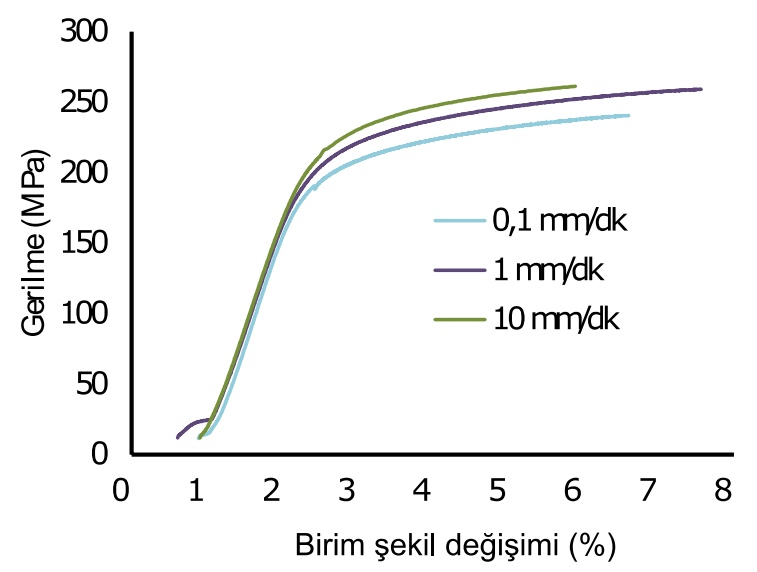

Şekil 3. Farklı çekme hızlarına bağlı olarak elde edilen gerilme-şekil değişsimi

\section{Johnson Cook malzeme modeli}

$\mathrm{Bu}$ malzeme modeli, malzemenin akma gerilmesini, pekleşme özelliklerini, şekil değiştirme, şekil değiştirme hızını ve yüksek sıcaklıktaki davranışını ifade eden bağıntıdır.

Johnson Cook modelinde gerilme açık bir formda aşağıdaki biçimde olduğu kabul edilmektedir [11]:

$$
\sigma=\left(a+b \varepsilon_{p}^{n}\right)\left(1+c \ln \frac{\dot{\varepsilon}}{\dot{\varepsilon}_{n}}\right)\left(1-(\hat{T})^{m}\right)
$$

Üstteki eşitlikle; $a$ akma gerilmesi, $b$ plastik pekleşme parametresi, $n$ plastik pekleşme üstü, $c$ şekil değişim hız katsayısı, $\dot{\varepsilon}$ şekil değişim hızı, $\dot{\varepsilon}_{0}$ referans şekil değişim hızı, $T^{*}$ sıcaklık etkisi ve $m$ ise sicaklık üssüdür.Johnson-Cook hasar modelinde şekil değişimi ise,

$$
\varepsilon_{f}=\left(D_{1}+D_{2} \exp \left(D_{3} \frac{\sigma_{m}}{\sigma_{v m}}\right)\right)\left(1+D_{4} \ln \frac{\dot{\varepsilon}}{\dot{\varepsilon}_{n}}\right)\left(1+D_{5}(\hat{T})^{m}\right)
$$

ile ifade edilip $D_{1}, D_{2}, D_{3}, D_{4}$ ve $D_{5}$ hasar parametreleri, $\sigma_{m}$ ortalama gerilme, $\sigma_{v m}$ vonmises gerilmesi, $\dot{\varepsilon}$ şekil değişim hızı, $\dot{\varepsilon}_{0}$ referans şekil değişis hızı ve $T^{*}$ ise sıcaklık etkisidir [11]. Sözü geçen bu D parametreleri, deneysel verilerin Denklem 2'de gösterilen denkleme uygulanıp eğri uydurma tekniğiyle belirlenir. Burada, sıcaklığın etkisi dâhil edilmediğimden $\mathrm{D}_{5}=0$ olur.
Başlangıçta, referans şekil değişim hızı olan 1 $\mathrm{mm} / \mathrm{dk}$ için $\left(\dot{\varepsilon}_{0}=\dot{\varepsilon}\right)$ hesaplama yapılmıştır. Dolayısıyla şekil değişim hızı katsayısı olan $c$ değerinin etkisi ortadan kalkmıştır. Çekme testinden elde edilen ölçümlerin Johnson Cook malzeme modelinde eğri uydurma sonucu sonucu $a=200.06 \mathrm{MPa}, b=414.65 \mathrm{MPa}$ ve $n=$ 0,604979 şeklinde bulunmuştur. Aynı yöntem hasar modeli için uygulandığında $\mathrm{D}_{1}=(0,0396)$, $\mathrm{D}_{2}=(0,1)$ ve $\mathrm{D}_{3}=(-20)$ olarak elde edilmiştir. Deneysel ölçüm ile modelden elde edilen değerler, Şekil 4'de verildiği üzere özellikle \% 2.5 ten büyük şekil değişimleri için birbirleriyle uyumlu oldukları gözlemlenmiştir.

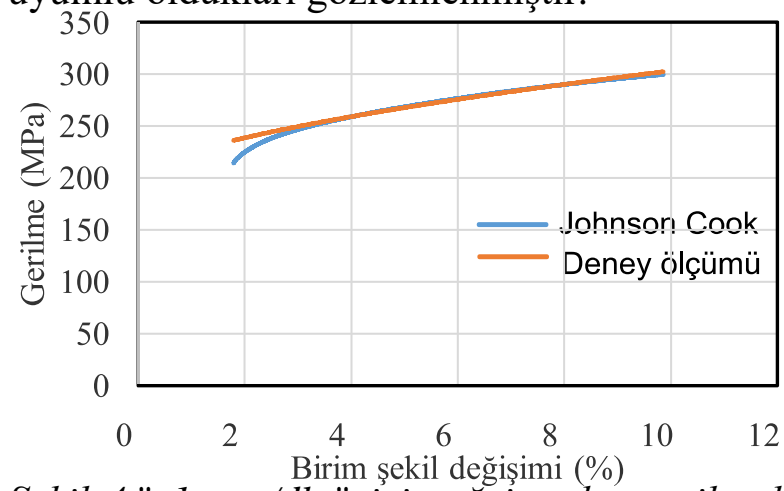

Şekil 4." $1 \mathrm{~mm} / \mathrm{dk}$ " için egrri uydurma ile elde edilen Johnshon-Cook malzeme model eğrisi ile deneysel ölçüm eğrisi

Şekil değişim hız etkisini işlemlere dahil etmek için $c$ katsayısının belirlenmesi gerekir. Bu amaçla, $1 \mathrm{~mm} / \mathrm{dk}$ hız ile yapılmış çekme testinin ham verilerinden elde edilen $a, b$ ve $n$ değerleri $10 \mathrm{~mm} / \mathrm{dk}$ hız ile yapılmış bir başka testinin ham verileriyle oluşturulmuş gerçek gerilme plastik şekil değiştirme grafiğginin üzerine yerleştirilir. $\mathrm{Bu}$ işlemde şekil değişim hızı faktörü olan $c$ katsayısının etkisi gözlenir. Şekil 5 'de eğri yerleştirme işlemi sonucunda elde edilen yeni eğri gösterilmiştir. Aynı işlemler diğer hızlar ve hasar modeli için gerçekleştirilmiş ve nihai olarak elde edilen Johnson Cook parametreleri Tablo 2'de verilmiştir. Malzemenin yoğunluğu $2700 \mathrm{~kg} / \mathrm{m}^{3}$ ve çekme testinden hesaplanan elastisite modülü ise $77.8 \mathrm{GPa}$ 'dır.

Tablo 2. Şekil değișim hızı etkisinin dikkate alınması sonucu hesaplanan malzeme modeli katsayılarl

\begin{tabular}{cccc}
\hline$a(\mathrm{~Pa})$ & $b(\mathrm{~Pa})$ & $n$ & $c$ \\
\hline 200060000 & 414659259 & 0,604979 & 0,059651 \\
\hline
\end{tabular}


Tablo 3. Şekil değiş̧im hızı etkisinin dikkate alınması sonucu hesaplanan malzeme hasar modeline ilişkin katsayılar

\begin{tabular}{cccc}
\hline $\mathrm{D}_{1}$ & $\mathrm{D}_{2}$ & $\mathrm{D}_{3}$ & $\mathrm{D}_{4}$ \\
\hline 0,0396 & 0,1 & -20 & 0,01 \\
\hline
\end{tabular}

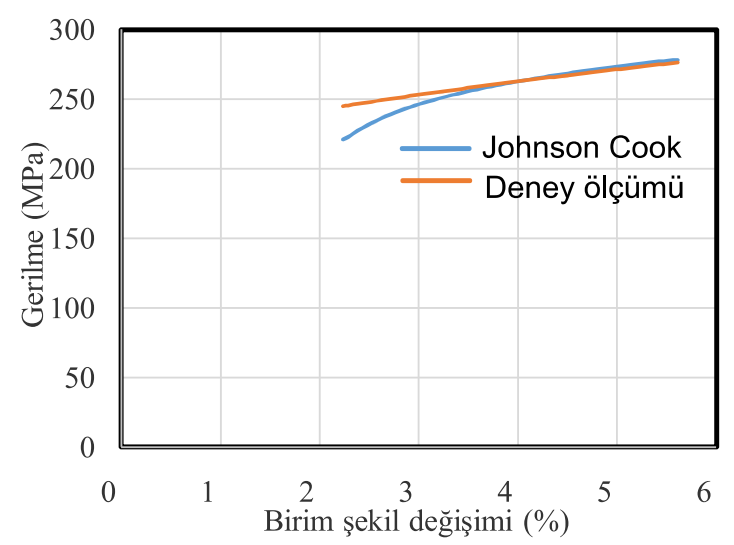

Şekil 5." $10 \mathrm{~mm} / d \mathrm{k}$ " için eğri uydurma ile elde edilen Johnshon-Cook malzeme model eğrisi ile deneysel ölçüm ĕgrisi

\section{Darbe testi ve sonlu elemanlar yöntemiyle doğrulama}

Darbe testi alüminyum alaşımlı jantların, maruz kalabileceği yanal darbelere karşı dayanımlarını belirlemek için uygulanan tahribatlı bir yöntemidir. Araç yükü de göz önünde bulundurularak, jantın kırılmaya karşı yeterli direnç göstermesi gerekir. Jant, test cihazına yer ekseni ile 13 derece açı yapacak şekilde bir flanş yardımı ile bağlanır. Sonra, rijit bir plaka 230 $\mathrm{mm}$ yüksekten jant üzerine serbest bırakılmasıyla test tamamlanır (Şekil 6).

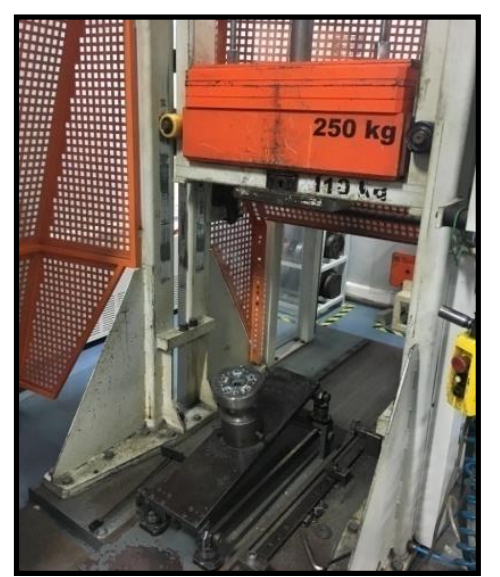

Şekil 6. Darbe testi

Jantların feder bölgeleri simetrik bir yapıdadır ancak göbek bölgesi federlere göre simetrik değildir. $\mathrm{Bu}$ nedenle jant modelinde göbek bölgesi ve feder bölgesinin ağ yapısı, geometrik olarak birbirinden ayrılmış ve bu şekilde ağ hazırlanmıştır.

Jant ölçüleri $6 \mathrm{~J}$ x 17'dir. Model üzerinde, jantın yük taşıyan bölgelerinde $1.9 \mathrm{~mm}$, diğer bölgelerinde ise 2.5 - $5 \mathrm{~mm}$ uzunluğunda piramit (tetrahedral) elemanlar kullanılarak ăg yapısı örülmüştür. Modelin tamamı 1397198 adet üç boyutlu elemandan oluşmaktadır. Jant modeline ilişkin tüm ağ yapısı Şekil 7'de gösterilmiştir.

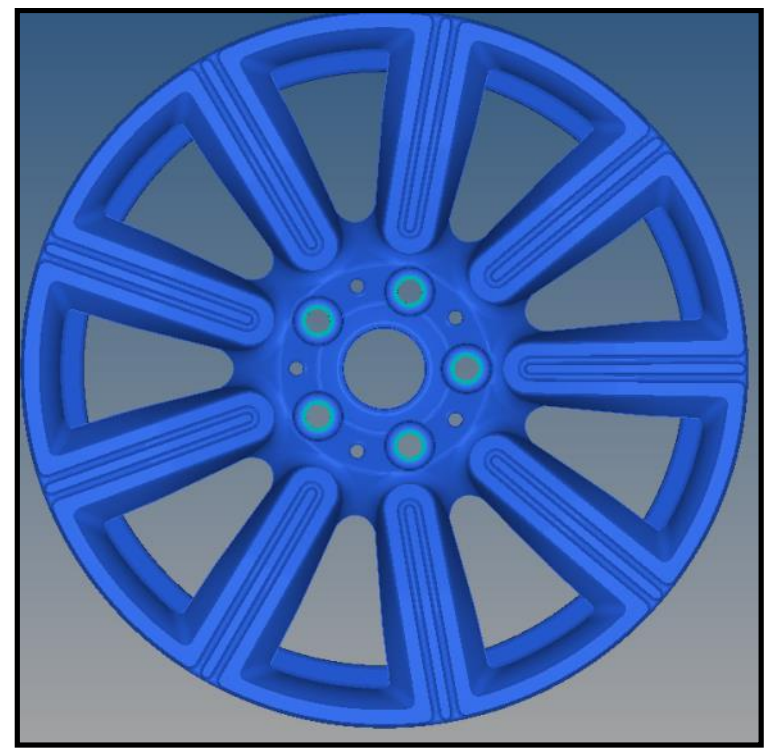

\section{Şekil 7. Jant modeline ilişkin sonlu elemanlar $a \breve{g} l$}

Sonlu elemanlar jant modeli, gerçek testteki gibi yer ekseniyle 13 derece bir açı olacak şekilde düzenlenip bijon ise yüzey ağlarından sabitlenmiştir. Jantın en üst noktasından temasa çok yakın pozisyonda rijit bir plaka tanımlanmıştır. Bu plaka gerçek testte $230 \mathrm{~mm}$ yükseklikten serbest düşme ile bırakılmaktadır. Ancak simülasyonda serbest düşme tanımlamak çözüm süresini gereksiz uzatacaktır. Bu nedenle simülasyonda oluşturulan rijit plaka jant modeline çok yakın bir pozisyona konumlandırılır ve ilk hız tanımlanır. İlk hız, plakanın $230 \mathrm{~mm}$ yükseklikten düşerek, temas noktasına değdiği andaki potansiyel enerji farkının kinetik enerjiye dönüştürmekle hesaplanmış ve değeri $2,12 \mathrm{~m} / \mathrm{s}$ 'dir (Şekil 8). 


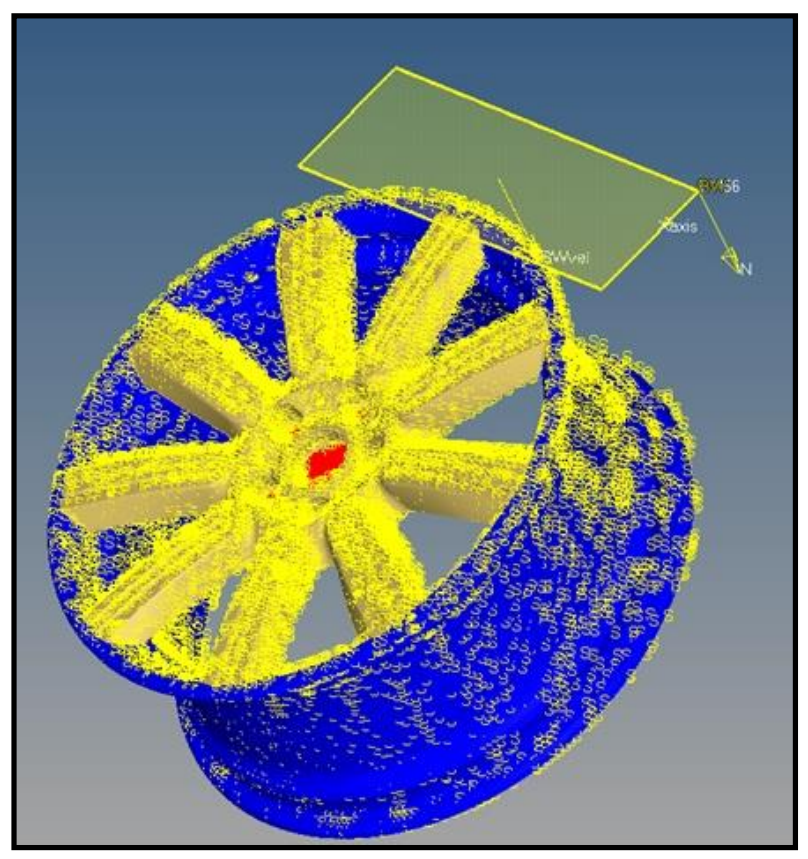

Şekil 8. Darbe testi simülasyon modeli

Darbe test simülasyonu bir önceki başlıkta elde edilen Johnson Cook malzeme ve hasar modeli parametrelerinin tanımlamasıyla analizler Radioss paket programı ile gerçekleştirilir [12]. Denklem 2'de verilen Johnson-Cook hasar modelindeki plastik şekil değişimi $\varepsilon_{\mathrm{f}}>0$ olması durumunda hasarın oluştuğu ve $\varepsilon_{\mathrm{f}}>0$ hasar kriterini barındıran elamanlar otomatik olarak modelden silinir. Simülasyon sonucunda jant modelinde oluşan çatlak veya hasarın derinliğine göre simülasyon sonucu yorumlanır. Standart bir darbe testi simülasyonunda şekil değişim hızı etkisi göz önünde bulundurulmamaktadır.

\section{Sonuçlar ve değerlendirme}

$\mathrm{Bu}$ çalışma kapsamında, malzeme modeline şekil değişim hızını etkileyen parametreler eklenerek daha gerçekçi simülasyonların yapılması hedeflenmiştir. Sınır şartları, deneysel yöntemdekilere benzer olarak tanımlanmış ve testler ile simülasyonlar arasında karşılaştırma yapılmıştır.

Başlangıçta, şekil değişim hızı etkisi göz ardı edilerek standart bir darbe testi simülasyonu tamamlanmıştır. Şekil 9'da görüldüğü gibi şekil değişim hızı etkisinin göz ardı edildiği simülasyonlarda, jantın bijon ile feder birleşim noktalarında hasar görülmektedir. Ön yüzeyde derin çatlak oluşmuş ancak komple ayrılma gerçekleşmemiştir. Kırılan bölgeler yüksek gerilme bölgeleridir. Şekil değişim hızının etkisini gösteren parametrenin ihmal edilmesiyle gerçekleştirilen simülasyonda çatlaklar oluşmuştur.

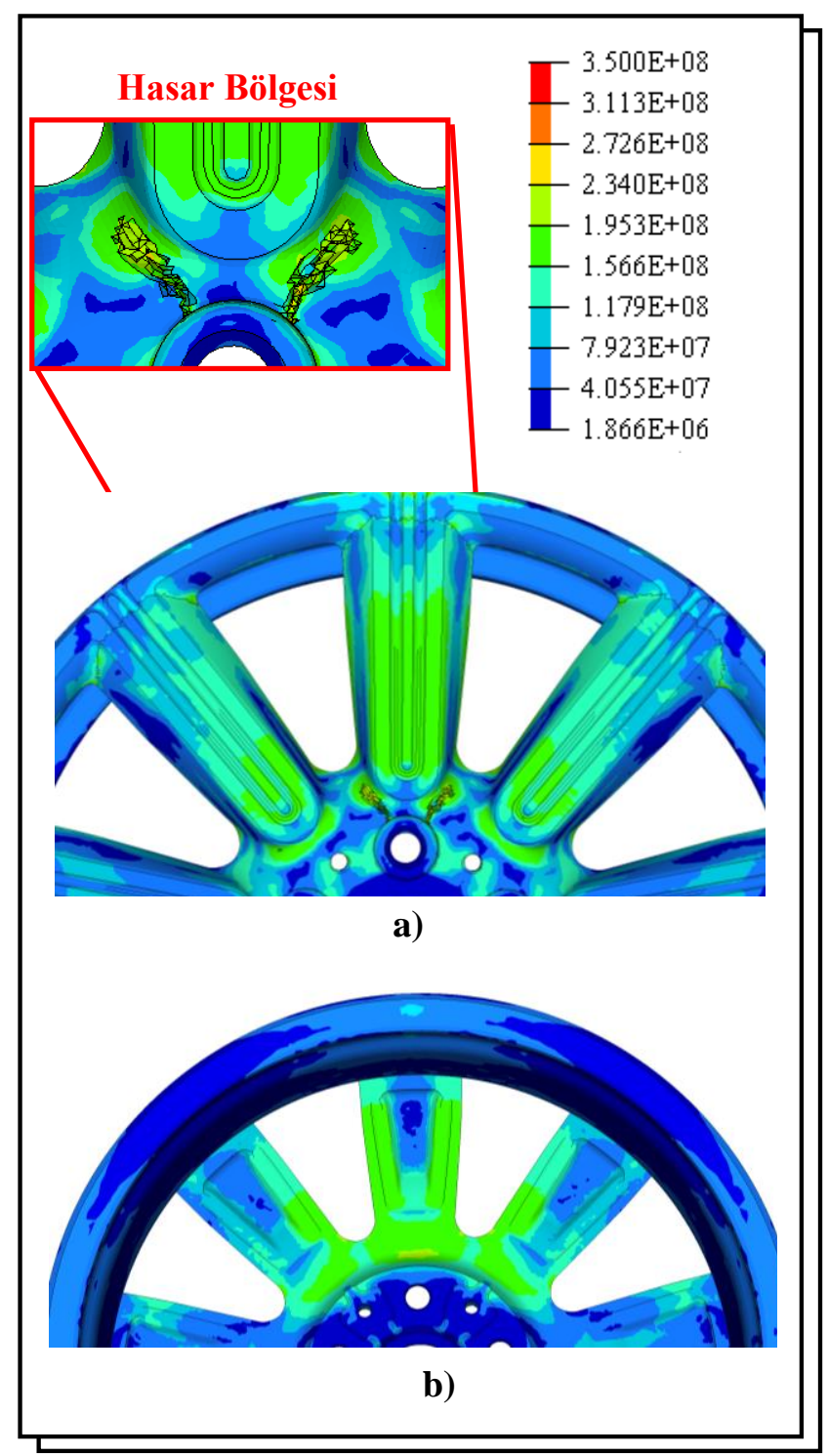

Şekil 9. Şekil değişim hızı etkisi göz ardı edilmiş darbe testi simülasyonu, a) Ön görünüss, b) Arka görünüş

Simülasyon sonuçlarını karşılaştırmak için aynı şartlar altında gerçek darbe testi tamamlanmıştır. $\mathrm{Bu}$ testler sonucunda jantlara penetrant muayenesi uygulanmış ve elde edilen sonuçlar Şekil 10'da verilmiştir. Görüldüğü üzere, yapılan gerçek testler sonucunda jantta 
her hangi bir hasar veya çatlak gözlenmemiştir. $\mathrm{Bu}$ da yapilan simülasyon ile test arasinda bir farklılık olduğu yorumunu ortaya çıkarmıştır. $\mathrm{Bu}$ nedenle simülasyonun geliştirilmesi gerektiği düşünülmüş ve sonuca büyük etkisi olduğu düşünülen malzeme modeline şekil değişim hızı faktörü eklenerek aynı şartlar altında simülasyon tamamlanmıştır.

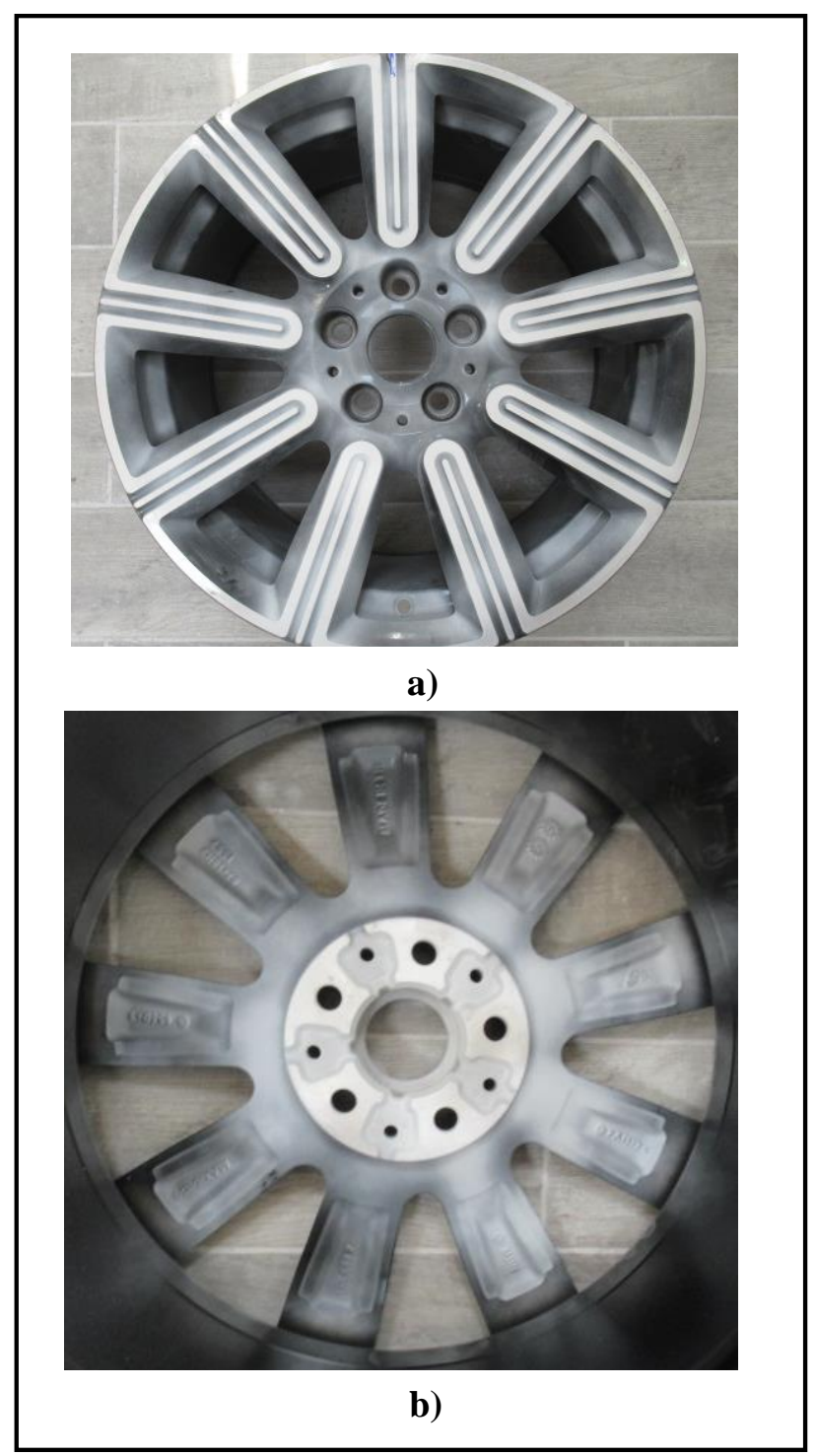

Şekil 10. Gerçek darbe test sonuçları

Şekil değişim hızı etkisinin dahil edildiği darbe testinin simülasyon sonuçları Şekil 11'de verilmiştir. $\mathrm{Bu}$ simülasyon sonucunda hasar görünmemektedir. Sadece bir kaç elemanın, kopma gerilmesi değerinin üzerine çıkması sonucu ihmal edilebilecek düzeyde hasarlar gerçekleşmiştir. Nitekim bu hasarlar tekil gerilmelerden oluşmuştur. Bir başka deyişle, bu bölgede yer alan piramit elemanlar diğerlerine nazaran daha keskin köşeler barındırdığından daha yüksek gerilmeler oluşmuştur. Bunun sonucu olarak ta bu elemanlarda kismi de olsa hasarlar tespit edilmiştir. $\mathrm{Bu}$ nedenle, bu simülasyon sonuçları, gerçek testte de herhangi bir hasar oluşmayacağını ön görmektedir. Nitekim Şekil 11'de, şekil değişim hız etkisinin tanımlandığı analizler, tanımlanmayana göre, daha gerçekçi sonuçlar verdiği görülmektedir.

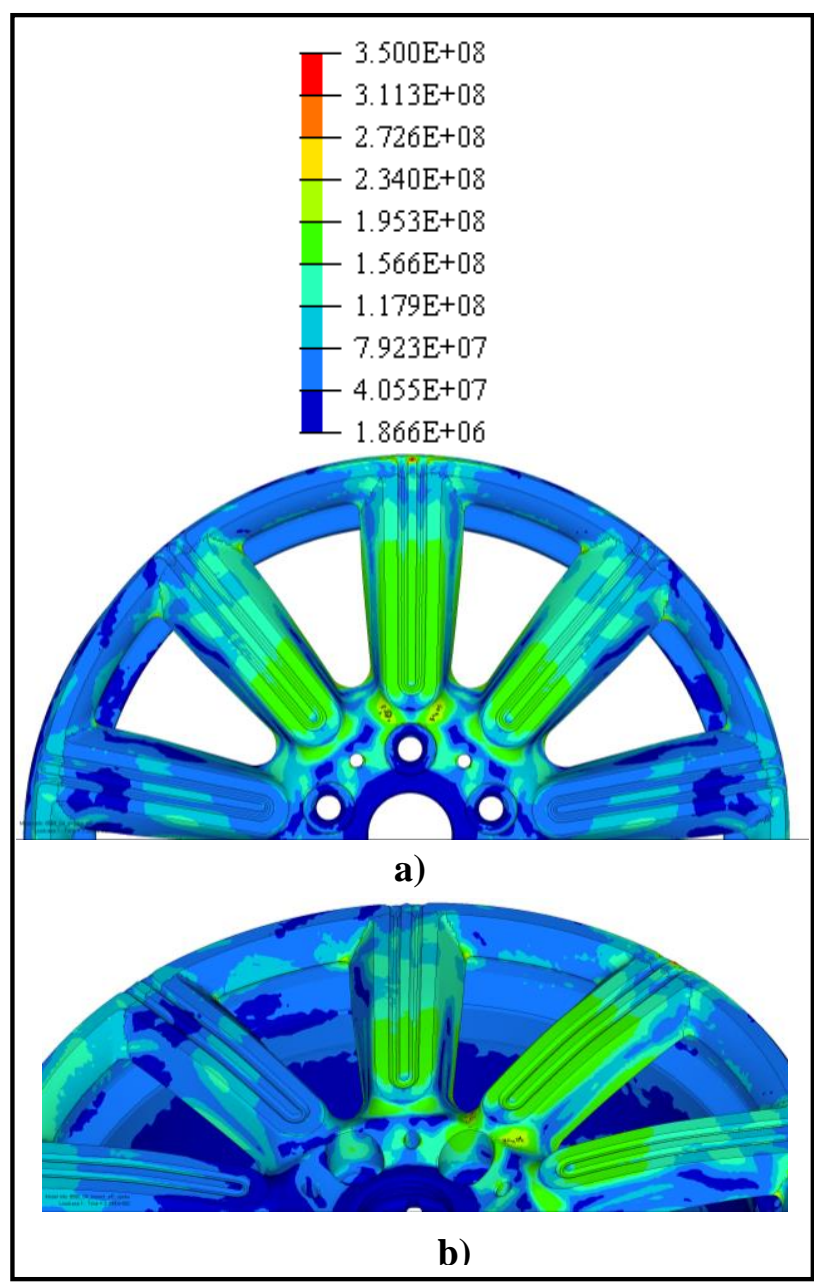

Şekil 11. Şekil değişim hızı etkisi dahil edilmiş darbe testi simülasyonu, a) Ön görünüş, b) Arka görünüş

Şekil değişim hızı etkisinin göz ardı edildiği, darbe testi simülasyonunda görülen, yüksek gerilme bölgesinin doğruluğunu kontrol etmek amaciyla tekrar bir gerçek darbe testi yapılmıştır. $\mathrm{Bu}$ yapılan darbe testinde, jantta bir çatlak hasarı oluşturmak ve bu bölgeyi doğrulamak için normal taşıması gerektiği ağırlıktan $80 \mathrm{~kg}$ daha yüksek bir ağırlık ile test gerçekleştirilmiş ve sonuçlar Şekil $12^{\prime}$ de 
gösterilmiştir. Görüldüğü üzere, jantın bijon ve feder birleşim bölgesinde hasar oluşmuştur. Ancak, jantın arkasında bir çatlak hasarı tespit edilmemiştir. $\mathrm{Bu}$ test sonuçlarında tespit edilen çatlak, Şekil 9'da görünen hasar ile aynı bölgede oluşmaktadır. $\mathrm{Bu}$ da jantın yüksek gerilme bölgesinin doğru tespit edildiği çıkarımının yapılmasına yardımcı olmaktadır.

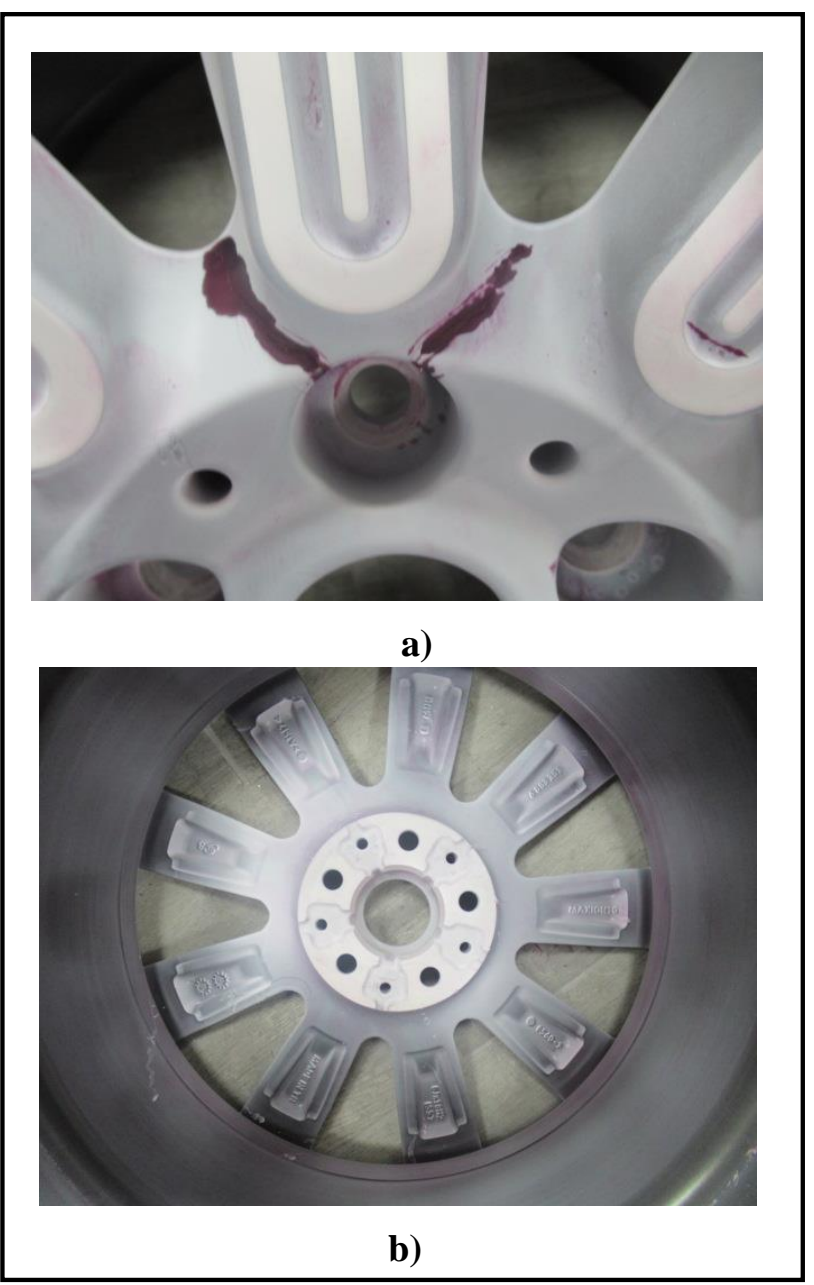

Şekil 12. Yüksek yük ile yapılan gerçek darbe testi, a) Ön görünüş, b) Arka görünüş

$\mathrm{Bu}$ çalışmada darbe testi simülasyonu iki farklı malzeme ve hasar modeli ile yapılmıștır. Bu iki malzeme ve hasar modeli arasindaki tek fark, şekil değişim hız etkisini tanımlayan parametrelerdir. Şekil değişim hızı etkisinin tanımlandığı simülasyon sonuçlarının gerçek test sonuçlarıyla daha uyumlu olduğu gözlenmiștir. Bir başka deyișle, şekil değiștirme hızı parametresinin dâhil edildiği sonlu elemanlar tekniğinden daha hassas sonuçlar elde edilmiştir. $\mathrm{Bu}$ sayede tasarım aşamasında daha doğru sonuçlar elde edilip, belki de daha hafif jantların tasarlanması mümkün olacaktır. Otomotiv endüstrisinde, daha doğru simülasyonlar ile birlikte daha hafif jantların tasarlanabilmesi, dolaylı yoldan yakıt tüketimini azaltmaya da fayda sağlayabilecektir. Sonuç olarak, hafif ticari araçlar için jant üretiminde kritik bir test olan sayısal darbe testinde şekil değiştirme hız parametresinin eklenmesiyle, ilerleyen çalışmalarda tekrarlı deneysel testler uygulamadan direkt nümerik yöntem ile jantın mekanik davranışları tespit edilebilecektir.

\section{Kaynaklar}

[1] Society of Automotive Engineers J175. (2001). Wheels-İmpact Test Procedures-Road Vehicles. SAE International Inc, Warrendale, PA, USA.

[2] Society of Automotive Engineers, (2016). J175-201603, Wheels Lateral Impact Test Procedure - Road Vehicles, SAE International Inc, Warrendale, PA, USA.

[3] Ayran, E., (2019). Alüminyum Alaşımlı Otomobil Jantlarında Deneysel Darbe Testlerinin Sonlu Elemanlar Yöntemiyle Doğrulanması, Yüksek Lisans Tezi, Ege Üniversitesi, İzmir, Türkiye.

[4] Şirin, U., (2017). Alüminyum Alaşımlı Otomobil Jantının Dinamik Testinin Modellenmesi ve Doğrulama Yaklaşımı, Yüksek Lisans Tezi, Ege Üniversitesi, İzmir, Türkiye.

[5] Yang, L., Yang, H., Tan, H., Hu, P., Cheng, X., Lu J., (2018) Impact test simulation and structural optimization of aluminum alloy A356.2 wheel hub, J. Phys.: Conf. Ser., 1074, 012068.

[6] Yuan X., Zhang L., Chen X., Du B., Li B., Fan L., Pan Y., (2012). Numerical simulation of aluminum alloy wheel $13^{\circ}$ impact test based on Abaqus, Applied Mechanics and Materials Vols,Trans Tech Publications, Switzerland, 1191-1196.

[7] Bandral S., Singh., (2018). Impact analysis of car alloy wheel rim using finite element analysis, International Journal of Engineering Engineering Research \& Technlogy, RDMEI Conf. Proc., 1-4.

[8] Chang, C.L., Yang, S.H., (2009). Simulation of wheel impact test using finite element method, Engineering Failure Analysis, 16, 1711-1719.

[9] Chen, Y., Clausen, A.H., Hopperstad, O.S., Langseth, M., (2009). Stress-strain behaviour of aluminium alloys at a wide range of strain rates, International Journal of Solids and Structures, 46, 3825-35.

[10] Altenhof, W., Ames, W., (2002). Strain rate effects for aluminum and magnesium alloys in finite element simulations of steering wheel armature impact tests, Fatigue Fract Engng Mater Struc, 25, 1149-1156.

[11] Johnson, G.R., Cook, W.H., (1985). Fracture characteristics of three metals subjected to various strains, strain rates, temperatures and pressures, Engineering Fracture Mechanics,.21(1), 31-48.

[12] Radioss Theory Manual, (2017), Large displacement finite element analysis, Altair Engineering. 